\title{
INDEFERIMENTO DE TUTELA PROVISÓRIA REQUERIDA PELO AUTOR: CONCESSÃO DE TUTELA JURISDICIONAL EM FAVOR DA PARTE ADVERSA POR VIA INDIRETA?
}

\author{
DENIAL OF MOTION FOR PROVISIONAL PROTECTIVE MEASURE \\ PRESENTED BY THE PLAINTIFF: A INDIRECT WAY TO GRANT A \\ PROTECTIVE MEASURE IN FAVOR OF THE DEFENDANT?
}

Flávio Henrique Siviero ${ }^{1}$

\begin{abstract}
Resumo: $O$ instituto da jurisdição é um dos alicerces do Direito Processual Civil, razão pela qual a correta compreensão de seu significado e de sua extensão é essencial ao domínio teórico da matéria. Com o objetivo de bem delimitar os termos do exercício da atividade jurisdicional, o presente artigo visa a aferir se o indeferimento de pedido de tutela provisória formulado pelo autor consiste, por via indireta, na concessão de tutela jurisdicional em favor da parte adversa. Metodologicamente, o artigo utiliza a revisão bibliográfica para estabelecer as premissas necessárias à solução do problema proposto. A partir dos estudos da doutrina especializada conclui-se que embora a rejeição definitiva da pretensão autoral em sentença de mérito importe em concessão de tutela jurisdicional em favor do réu por via indireta o mesmo não se pode afirmar em relação ao indeferimento de pedido de tutela provisória.
\end{abstract}

Palavras-chave: Direito Processual Civil. Tutela provisória. Princípio dispositivo. Princípio da congruência. Tutela jurisdicional.

Abstract: The institute of jurisdiction is one of the foundations of the Civil Procedure, which is why the correct understanding of its meaning and extent is essential to the theoretical mastery of the subject. In order to clearly define the terms of the exercise of the jurisdictional activity, this article aims to assess whether the rejection of the motion for provisional protection measure presented by the plaintiff consists, indirectly, in the granting of jurisdictional protection in favor of the oposite party. Methodologically, the paper uses literature review to establish the necessary premises to solve the proposed problem. From the studies of the specialized doctrine, it is concluded that although the definitive rejection of the plaintiff's claim in a judgment implies, indirectly, the granting of judicial protection in favor of the defendant, the same cannot be said regarding the rejection of the request for provisional protection measure.

Keywords: Civil Procedure. Provisional protection measures. Principle of party disposition. Principle of congruence. Jurisdictional protection.

\footnotetext{
${ }^{1}$ Defensor Público Federal titular do $11^{\circ}$ Ofício Previdenciário da Defensoria Pública da União em São Paulo. Mestrando em Direito Processual Civil pela PUC/SP. Graduou-se em Direito pela Universidade Presbiteriana Mackenzie. Tem experiência na área de Direito, com ênfase em Direito Previdenciário, Processual Civil e Civil. Antes de ingressar na DPU foi servidor efetivo dos quadros do Tribunal de Justiça de São Paulo e exerceu advocacia privada.

Revista Auditorium, Rio de Janeiro, v. 25, n. 52, p. 107-125, jul./out. 2021
} 
Recebido em: 29/09/2021

Aceito para publicação em: 27/10/2021 


\section{INTRODUÇÃO}

O presente artigo visa a esclarecer se o indeferimento de tutela provisória requerida pelo autor pode ser compreendido como concessão de uma tutela jurisdicional, ainda que por via indireta, em favor do réu.

Com o intuito de apresentar uma solução ao problema proposto serão analisados os conceitos de tutela, de tutela de direitos, de jurisdição, de tutela jurisdicional, o princípio dispositivo que decorre da inércia da jurisdição e o princípio da congruência, que norteia a necessária correlação entre pedido e provimento jurisdicional, com o objeto de construir uma base teórica sólida de onde serão retiradas as premissas necessárias à propositura de uma resposta bem fundamentada.

A seguir se analisará se é possível considerar que a rejeição do pedido autoral na sentença definitiva pode ser considerada uma expressão da tutela jurisdicional em benefício do réu tanto em sede de ações dúplices como em sede de ações que não são dotadas de natureza ambivalente.

Por fim, confrontar-se-á o panorama jurídico resultante da rejeição definitiva do pedido com o do indeferimento de tutela provisória para que se possa aferir se a decisão denegatória de tutela provisória importa ou não em uma tutela jurisdicional em prol do réu.

\section{CONCEITO DE TUTELA JURISDICIONAL}

Para que seja possível levar a cabo a missão de sugerir uma resposta para a questão que motivou a elaboração do presente artigo, curial se revela em primeiro lugar estabelecer o que exatamente se entende por tutela jurisdicional, haja vista que apenas a partir da correta compreensão do instituto é que será possível afirmar se 0 indeferimento de pedido de tutela provisória formulado por uma das partes enseja, por via indireta, a concessão de tutela jurisdicional em favor da outra.

Destarte, antes de se adentrar nas questões mais problemáticas que se pretende enfrentar no curso deste trabalho, afigura-se recomendável tecer algumas breves considerações sobre a definição de tutela jurisdicional. 
Com esse propósito, serão analisados no presente tópico os conceitos de tutela, de tutela de direitos, de jurisdição e, por fim, de tutela jurisdicional.

\subsection{Tutela}

Embora a tutela jurisdicional seja a espécie do gênero tutela usualmente estudada pela doutrina que se dedica ao Direito Processual Civil (BRASIL, 2015), não se pode olvidar que a tutela jurisdicional não é a única expressão da tutela.

Assim sendo, antes de se descer à modalidade adjetivada da tutela jurisdicional, é conveniente esclarecer sobre o que exatamente se está a tratar ao se falar sobre o substantivo tutela.

Conquanto o termo tutela seja equívoco, apresentando diversas acepções (GUIMARÃES, 2019, p. 234), o significado que melhor exprime o conceito de tutela contido na expressão tutela jurisdicional é o de proteção ou amparo.

Destarte, será esse o sentido com que o vocábulo será empregado no presente trabalho.

\subsection{Tutela de direitos}

Estabelecida a ideia de que tutela corresponde à proteção ou amparo de alguma coisa, parece lógico se afirmar que tutela de direitos nada mais é do que proteção de direitos.

A necessidade de proteção de um direito ganha relevância diante da existência de uma lide, assim entendido, o conflito de interesses qualificado por uma resistência à pretensão.

Em um contexto de lide a tutela de direitos dos envolvidos há de se manifestar por meio de uma das relativamente poucas alternativas possíveis de resolução do litígio.

São meios em que os próprios interessados efetivamente resolvem o litígio a autotutela, que é a imposição da vontade de um litigante ao outro, com sacrifício dos interesses deste, e a autocomposição, que é forma de solução na qual há consentimento voluntário de um dos envolvidos em abrir mão, no todo ou em parte, de seus interesses em prol de seu adversário (DIDIER JÚNIOR, 2017, p. 186-187). 
Existe, ainda, a heterocomposição, forma de resolução na qual "um terceiro resolve a ameaça ou crise de colaboração na realização do direito material entre as partes" (MARINONI; ARENHART; MITIDIERO, 2017a, p. 154). Esse terceiro pode ser um particular escolhido pelas partes, hipótese na qual teremos arbitragem, ou o Estado no desempenho da função jurisdicional estatal.

\subsection{Jurisdição}

Outro dos conceitos cuja compreensão do que vem a ser é indispensável para entender o que é tutela jurisdicional é o de jurisdição.

Conceituar jurisdição em poucas palavras revela-se uma tarefa espinhosa ante a diversidade de posicionamentos a respeito desse milenar instituto encontrados na doutrina.

A título de exemplo e com base em excelente trabalho de compilação do posicionamento de juristas clássicos sobre o tema feito por Daniel Amorim Assumpção Neves (2014, p. 4) podemos observar que Chiovenda afirmava que a jurisdição era entendida como a atuação da vontade concreta do Direito, Carnelutti compreendia que essa atuação derivava da circunstância de a sentença fazer concreta a norma geral e que Kelsen defendia que jurisdição se tratava do fenômeno de criar uma norma individual com base na norma geral.

De igual forma, não se pode olvidar que de acordo com a obra clássica de Cintra, Grinover e Dinamarco (2013, p. 147) o termo jurisdição encerra em si não apenas uma acepção, mas três, pois significa poder como expressão da capacidade estatal de decidir e impor suas decisões, função como o encargo dado ao Estado de promover a pacificação social e atividade como a série de atos judiciais tendentes ao exercício do mister de decidir.

De toda forma, sem embargo da riqueza da discussão doutrinária sobre o verdadeiro significado da expressão jurisdição, que já rendeu estudos profundos exclusivamente a respeito do tema, para os fins do presente trabalho se revela necessário estabelecer um critério preciso e relativamente conciso sobre o que se considera jurisdição a partir da perspectiva de que dela pode emanar a proteção de direitos. 
Nessa senda, parece adequada a definição trazida por Humberto Theodoro Júnior (2017, p. 138) no sentido de que "jurisdição é a função do Estado de declarar e realizar, de forma prática, a vontade da lei diante de uma situação jurídica controvertida".

\subsection{Tutela jurisdicional}

Estabelecidos os conceitos de tutela e de jurisdição que foram explicitados alhures, compreender o significado de tutela jurisdicional não se revela uma tarefa complicada.

A rigor, ao se assimilar que tutela nada mais é do que proteção e que jurisdição (no que interessa ao conceito de tutela jurisdicional ao menos) é a função estatal de dar concretude ao ordenamento jurídico soa bastante intuitivo que tutela jurisdicional é a proteção de direitos pela via jurisdicional.

Ressalte-se, por oportuno, que a conclusão ora defendida encontra ressonância na doutrina, como se infere do escólio de Cassio Scarpinella Bueno (2020, p. 934) no sentido de que tutela jurisdicional é a "proteção outorgada pelo juiz quando reconhece o direito cuja afirmação de lesão ou ameaça impulsiona e justifica a atuaçã̃o do Poder Judiciário".

\section{PRINCÍPIO DISPOSITIVO E PRINCÍPIO DA CONGRUÊNCIA}

Uma das mais destacadas características da jurisdição é sua inércia, cristalizada em nosso direito positivo no art. $2^{\circ}$ do Código de Processo Civil (BRASIL, 2015), que estatui que como regra a atividade jurisdicional não pode ser exercida sem que um interessado provoque a atuação do órgão julgador.

A vedação à atuação oficiosa do órgão jurisdicional sem requerimento prévio do interessado, a quem cabe delimitar as questões que serão submetidas a julgamento, é denominada pela doutrina (ALVIM, 2020, p. 234) de princípio dispositivo.

A inércia, todavia, não impede que uma vez provocada a jurisdição o processo siga seu curso independentemente de novas manifestações do autor da ação no sentido de seu prosseguimento. 
Isso porque o impulso oficial impõe que uma vez deflagrada a marcha processual ela deverá prosseguir até que ocorra a extinção do feito mediante sentença terminativa, nas hipóteses do art. 485 do Código de Processo Civil, ou sentença definitiva, nos casos previstos no art. 487 do Código de Processo Civil, produzindo os efeitos que the são próprios independentemente da vontade das partes envolvidas (BRASIL, 2015).

Decorrência da inércia da jurisdição, o princípio da congruência - também chamado de princípio da adstrição -, preceitua que o juiz apenas pode acolher pedidos nos limites em que requeridos (CÂMARA 2017, p. 31; DONIZETTI, 2017, p. 578; GONÇALVES. 2020, p. 290). Aludido princípio encontra previsão legal expressa no art. 141 e no art. 492 do Código de Processo Civil.

O princípio da congruência não impede, contudo, que certos provimentos jurisdicionais sejam concedidos sem que jamais tenham sido requeridos pelas partes nas hipóteses que a própria lei prevê que tais provimentos são consequência necessária do acolhimentos de pedidos efetivamente formulados ou da própria resolução da demanda.

Trata-se do que se convencionou chamar de pedidos implícitos (DIDIER JÚNIOR, 2017, p. 666), pois por força de lei se considera que tais pedidos devem ser apreciados pelo julgador como se constassem da petição inicial ainda que a parte autora não os tenha apresentado explicitamente.

A razão de ser tanto da inércia da jurisdição como de seu corolário, o princípio da correlação, é o de preservar a imparcialidade do julgador (CINTRA; GRINOVER; DINAMARCO, 2013, p. 64), que poderia ficar comprometida caso a ele coubesse não apenas apreciar aquilo que the fosse requerido, mas também ele própria tomar a iniciativa de deduzir pretensões em favor de alguém, pois parece pouco provável que um ser humano que em um primeiro momento formou convicção no sentido de que determinado pedido era cabível possa posteriormente apreciar o referido pedido isento de qualquer predisposição de acolhê-lo.

De igual forma, ao discorrer sobre a melhor interpretação a ser dada ao art. 493 do Código de Processo Civil (BRASIL, 2015), Marinoni, Arenhart e Mitidiero lecionam em sua obra (2017b, p. 596) que "quando se pensa em congruência, 
afirma-se correntemente que sua finalidade é evitar que a jurisdição atue de ofício, o que poderia comprometer sua imparcialidade".

\section{REJEIÇÃO DO PEDIDO EM SEDE DE COGNIÇÃO EXAURIENTE COMO CONCESSÃO DE TUTELA JURISDICIONAL EM FAVOR DO RÉU}

Uma vez que se estabeleceu que a jurisdição não pode se manifestar de ofício, ou pelo menos que em regra não pode, e que aos juízes apenas é dado acolher pedidos nos estritos contornos do quanto requerido, parece intuitivo afirmar que somente aquele que formulou um pedido pode receber uma tutela jurisdicional em seu favor.

Acolher tal proposição levaria à conclusão de que um réu - e aqui se está a tratar da parte que apenas figura no polo passivo de um processo, não do réu que apresentou pedido contraposto em procedimento compatível com essa medida, muito menos de réu que se tornou autor ao apresentar reconvenção em processo que inicialmente foi movido em seu desfavor e com isso se tornou reconvinte - não teria como obter uma tutela jurisdicional em seu benefício.

Essa linha de raciocínio, todavia, não aparenta corresponder à realidade ao se dedicar maior reflexão sobre o assunto.

Isso porque certos efeitos das decisões são consequências naturais dos pronunciamentos judiciais mesmo que não haja pedido em relação a eles e que a decisão seja silente a seu respeito.

Tanto é assim que não há como se questionar que haverá formação de coisa julgada em favor do vencedor do processo, ainda que nenhuma das partes tenha requerido a medida e que a respectiva sentença irá transitar em julgado independentemente de menção expressa sobre isso no bojo da decisão.

Para melhor explicitar as consequências dos pronunciamentos judiciais que autorizam afirmar que é possível reconhecer que um réu pode sim ter uma tutela jurisdicional concedida em seu benefício revela-se conveniente, por razões metodológicas, analisar separadamente duas espécies de ações distintas: as ações dotadas de caráter dúplice e as ações que não são dotadas dessa natureza. 


\subsection{Ações dúplices}

Ações dúplices são aquelas nas quais não há exatamente autor e réu em lados antagônicos do processo, mas sim partes que figuram simultaneamente nos pólos ativo e passivo da relação processual.

Isso ocorre em hipóteses nas quais o direito material em discussão é de tal natureza que uma sentença de mérito a seu respeito necessariamente há de colocar o bem da vida litigioso nas mãos de uma das partes e negá-lo à outra, pouco importando quem deu causa à instauração do processo ou ainda que o réu não tenha apresentado um pedido perante o Poder Judiciário.

Não por outro motivo, encontra-se na doutrina entendimento (MEDINA, 2017, p. 412) no sentido de que em ações dúplices ambas as partes assumem concomitantemente as condições de autor e réu.

Talvez o mais emblemático exemplo de ação dúplice seja o das ações possessórias, típico caso no qual a relação jurídica de direito material - estabelecer qual das partes tem a melhor posse - obriga o magistrado a (i) ou reconhecer que a posse do autor (em sentido formal) é a melhor e por conta disso prevenir ou fazer cessar o esbulho ou turbação praticado pelo réu (novamente, em sentido formal) ou (ii) reconhecer que a posse do réu é melhor e em decorrência disso impedir que o autor a perturbe.

Não obstante, as possessórias não são as únicas ações dúplices em nosso sistema, podendo-se ainda citar como ações com essa característica as declaratórias em geral, as de exigir contas e as demarcatórias.

Nas ações declaratórias tanto o acolhimento como à rejeição do pedido formulado por qualquer das partes encerra a crise de certeza (NEVES, 2014, p. 41) a respeito da relação jurídica, podendo a resposta que põe termo à dúvida beneficiar qualquer das partes envolvidas no litígio.

Nas ações de exigir contas, superada a primeira fase do procedimento no qual se define se há ou não o dever de prestação de contas, há de ser proferida sentença na qual se apurará saldo em favor do autor ou do réu (DONIZETTI, 2020, p. 716).

Nas ações demarcatórias a fixação dos limites dos imóveis pode acabar por revelar que parte do terreno que originalmente se pensava ser do autor em verdade pertence ao réu. 
Como se vê, em todos esses casos o réu pode acabar obtendo uma situação jurídica mais favorável do que aquela em que se encontrava quando o autor deu ensejo à instauração do processo mesmo sem que aquele formule pedido em seu favor.

Para além das já mencionadas ações, não se pode ainda deixar de mencionar a ação direta de inconstitucionalidade (ADI) e a ação direta de constitucionalidade (ADC), ambas ações de controle abstrato de constitucionalidade, como ações dúplices.

O registro se revela pertinente, pois embora se tratem de ações declaratórias, o que poderia atrair a simples incidência da regra geral de que ações declaratória são dúplices, elas possuem particularidades como o fato de ensejarem um processo objetivo no qual não há um caso concreto (MORAES, 2006, p. 607) a ser decidido ou mesmo partes em sentido próprio, o que torna inaplicável o raciocínio de que seriam dúplices em razão da necessidade de se reconhecer o direito sobre o bem a vida a uma das partes litigantes.

Em verdade, o caráter ambivalente das referidas ações abstratas não decorre de uma relação jurídica de direito material, mas sim do fato de que seus objetos são opostos e mutuamente prejudiciais (MENDES; COELHO; BRANCO, 2010, p. 1.291-1.292).

Feitas essas considerações sobre as ações dúplices, parece intuitivo concluir que nas ações propriamente dúplices - e com isso ressalva-se as ações de processo objetivo de controle abstrato de constitucionalidade no qual não há partes - a improcedência do pedido apresentado pelo autor importa na tutela de direitos do réu pela via jurisdicional, ou seja, em tutela jurisdicional em favor de parte que não formulou pedido algum ao Poder Judiciário.

É bem verdade que nesses casos se poderia argumentar que ao exercer seu direito de defesa pleiteando a rejeição do pedido autoral o réu estaria apresentando um pedido ao Poder Judiciário e que, portanto, não haveria provimento jurisdicional em prol de alguém que não o requereu.

Tal argumento, todavia, não merece acolhida por duplo fundamento.

O primeiro é que quando o réu se defende, seja ao negar a ocorrência de fatos narrados pelo autor, seja ao emprestar aos contornos fáticos apresentados Revista Auditorium, Rio de Janeiro, v. 25, n. 52, p. 107-125, jul./out. 2021 
consequências jurídicas distintas daquelas requeridas pela parte adversa, seja, ainda, por alegar fato impeditivo, modificativo ou extintivo do direito autoral ele não exerce direito de ação, mas sim direito de defesa.

O segundo, e provavelmente o mais robusto, fundamento é o de que ainda que o réu seja revel e que não seja caso de atuação de curador especial, ou seja, que não tenha sido ofertada qualquer manifestação do réu pugnando pela rejeição do pedido, ainda assim a sentença de improcedência Ihe trará os mesmos efeitos favoráveis que adviriam caso ele tivesse ofertado contestação.

Nessa linha de ideias, parece de difícil refutação à tese de que nas ações dúplices a relação jurídica de direito material faz com que necessariamente a rejeição do pedido autoral corresponda à concessão de uma tutela jurisdicional em favor do réu.

\subsection{Ações não dúplices}

A problemática relacionada à concessão de tutela jurisdicional em prol do réu em caso de improcedência do pedido autoral ganha maior complexidade nas ações que não são dotadas de natureza dúplice.

Isso porque, ao contrário do que ocorre com as ações ambivalentes, a relação jurídica de direito material controvertida não impõe que a rejeição do pedido do autor aumente o patrimônio jurídico do réu de maneira direta.

Contudo, ainda que a relação de direito material não seja relevante nesses casos, ainda assim não se pode olvidar que ao menos um efeito fatalmente decorrerá da sentença de improcedência com aptidão de beneficiar o réu: a formação de coisa julgada material.

Como é cediço, o art. 50, XXXVI, da Constituição Federal (BRASIL, 1988) reconhece 0 instituto da coisa julgada, 0 art. 60 , § $3^{\circ}$, da Lei de Introdução às normas do Direito Brasileiro (BRASIL, 1942) estabelece que a coisa julgada é a decisão judicial irrecorrível e o art. 502 do Código de Processo Civil explicita que a coisa julgada material torna a decisão por ela acobertada imutável e indiscutível.

Em relação ao que dispõe a Lei de Introdução às normas do Direito Brasileiro (BRASIL, 1942) sobre coisa julgada, não constitui preciosismo salientar que o legislador não adotou a melhor técnica ao tratar do instituto, pois confunde a Revista Auditorium, Rio de Janeiro, v. 25, n. 52, p. 107-125, jul./out. 2021 
essência da coisa julgada com o momento em que ela surge (MARINONI; ARENHART; MITIDIERO, 2017a, p. 499).

De toda forma, para além do debate doutrinário sobre a coisa julgada ser qualidade da decisão judicial de que não se possa mais recorrer, e não a decisão propriamente dita, o que mais interessa aos propósitos do presente artigo é saber que essa qualidade que reveste a decisão a torna imutável e indiscutível.

Tendo em vista que com sua vitória sobre o autor, que teve seu pedido rejeitado, o réu não apenas deixa de perder algo no próprio processo em que proferida a decisão, mas também passa a ficar blindado contra novas investidas do autor em relação ao quanto decidido, certo é que a decisão coberta pelo manto da coisa julgada o coloca em uma posição jurídica mais favorável do que aquela em que ele se encontrava antes, o que conduz à conclusão de que a improcedência do pedido autoral implica, por via indireta, tutela jurisdicional conferida em prol do réu.

Corroborando o entendimento de que a vitória do réu importa em concessão de tutela jurisdicional em seu favor Cassio Scarpinella Bueno (2020, p. 110) ensina que:

É por esta razão que se mostra correto o entendimento de que a rejeição do pedido formulado pelo autor enseja a prestação de tutela jurisdicional para o réu. O Estado-juiz, ao declarar que o direito lesionado ou ameaçado não pertence ao autor, que o comportamento do réu (ou a ausência dele) não viola nem ameaça o ordenamento jurídico, ao contrário do que afirma o autor em sua petição inicial, reconhece, para todos os fins, a correção da posição ocupada pelo réu.

Este reconhecimento judicial da postura do réu - é bastante frequente referir-se a ela como uma declaração de que o autor não tem o direito que afirmava ter em face do réu - gera efeitos relevantes para o plano do processo e, mais do que isto, para o plano material também. Por se tratar de decisão que analisa o mérito, isto é, que examina a juridicidade do conflito supostamente existente pelas partes de acordo com a perspectiva do autor, a decisão tende a transitar, como se costuma afirmar, materialmente em julgado. Transitando em julgado, ela passa a ostentar imutabilidade e, por aqueles fundamentos, aquela mesma situação material já não poderá mais ser rediscutida entre aquelas partes e perante quaisquer órgãos jurisdicionais. Neste sentido, o réu protegeu-se suficiente e adequadamente com o exercício da função jurisdicional. Por isto ele recebe tutela jurisdicional. (BUENO, 2020, p. 110) 
Além da formação da coisa julgada material em favor do réu, que tende a ocorrer em todos os processos nos quais é proferida sentença de mérito rejeitando o pedido do autor, é de se observar ainda que a sentença de improcedência pode também criar título executivo em favor do réu. Referido título judicial pode ser objeto de cumprimento nos próprios autos do processo em que se originou.

A Corte Especial do Superior Tribunal de Justiça ao apreciar o REsp 1.324.152 (BRASIL, 2016a) e decidir controvérsia relacionada à correta interpretação do art. $475-N$, I, do CPC/73 em sede de recurso repetitivo firmou a tese de que:

A sentença, qualquer que seja sua natureza, de procedência ou improcedência do pedido, constitui título executivo judicial, desde que estabeleça obrigação de pagar quantia, de fazer, não fazer ou entregar coisa, admitida sua prévia liquidação e execução nos próprios autos. (BRASIL, 2016a)

Conquanto o caso concreto levado ao STJ dissesse respeito a dispositivo do revogado $\mathrm{CPC} / 73$, curial se revela observar que não há motivo para se cogitar de superação do entendimento firmado pelo aludido Tribunal Superior no precedente qualificado em tela, haja vista que sua própria Corte Especial fez constar do corpo do acórdão lavrado ${ }^{2}$ que $o$ atual Código de Processo Civil tem regra com a mesma redação.

É bem verdade que normalmente a sentença de improcedência de um pedido que estabeleça a existência de obrigação em desfavor do autor normalmente decorre do insucesso de uma ação declaratória, como por exemplo uma revisional de contrato (ação que embora possa conter em seu bojo algum pedido condenatório ou constitutivo tem carga predominantemente declaratória), o que poderia sugerir que na realidade a formação de título executivo contra o autor, no mundo dos fatos, só ocorreria em ações declaratórias, hipótese na qual que incidiria o regramento das ações dúplices em geral.

É interessante observar, todavia, que mesmo em ações que não são predominantemente declaratórias é possível que ocorra o reconhecimento de uma obrigação do autor por cumprir.

\footnotetext{
2"A solução do problema envolve a correta interpretação do artigo 475-N do Código de Processo Civil, com as modificações da Lei 11.232/2005, e que já está revogado. No entanto, o novo CPC contém regra com a mesma redação, daí a atualidade da decisão a ser proferida."

Revista Auditorium, Rio de Janeiro, v. 25, n. 52, p. 107-125, jul./out. 2021
} 
Um exemplo de ação constitutiva na qual é possível se reconhecer obrigação de pagar do autor é a ação de adjudicação compulsória, pois nela a parte autora afirma que já pagou o preço acertado por determinado bem imóvel e que o réu se recusa a lhe outorgar a escritura necessária para registrar a transferência do bem junto ao cartório de imóveis.

Nesse caso, se ao final do processo ficar decidido que o autor não pagou a integralidade do preço seria possível ao réu exigir o cumprimento de sentença pela parcela em aberto com base no entendimento sob análise.

Ter-se-ia, portanto, um caso de formação de título executivo em favor do réu em ação que não é dotada de natureza declaratória.

Destarte, seja pela formação de coisa julgada material, que é regra nos processos em que há sentença definitiva, seja pela formação de título executivo, circunstância que pode ou não se apresentar, a depender do reconhecimento da existência de uma obrigação não cumprida a ser adimplida pelo autor, conclui-se que a rejeição do pedido do autor ao final do processo importa em concessão de tutela jurisdicional em benefício do réu.

\section{INDEFERIMENTO DO PEDIDO DE TUTELA PROVISÓRIA}

Assentadas as premissas que levaram à conclusão de que quando o pedido do autor é julgado improcedente há tutela jurisdicional em favor do réu, outra questão que se apresenta é a de se o indeferimento de tutela provisória requerida pelo autor também consistiria na concessão de tutela de direitos pela via jurisdicional em prol do réu.

Ao contrário do que ocorre com a sentença definitiva, na qual o julgador exerce cognição exauriente a respeito da questão submetida a sua apreciação, decidindo qual das partes tem razão, nas tutelas provisórias o juiz exerce mera cognição sumária, concedendo provimento em benefício da parte aparenta ter razão.

Como se infere da leitura do art. 294, caput, do Código de Processo Civil, a tutela provisória pode se fundamentar em urgência ou em evidência (BRASIL, 2015).

No caso da tutela de urgência ela é concedida com amparo no art. 300, caput, do Código de Processo Civil porque o tempo é inimigo do direito, motivo pelo qual se Revista Auditorium, Rio de Janeiro, v. 25, n. 52, p. 107-125, jul./out. 2021 
impõe a concessão de medida que preserve o resultado útil do processo ou que adiante a própria entrega do bem da vida almejado pela parte para evitar dano irreparável ou de difícil reparação (BRASIL, 2015).

Tipicamente se estará diante de uma tutela cautelar no primeiro caso e de uma tutela antecipatória (ou uma antecipação dos efeitos da tutela final) no segundo.

No caso da tutela de evidência prevista no art. 311 do Código de Processo Civil o debate sobre a necessidade de concessão em caráter urgente da medida não se apresenta. $O$ que ocorre é que a expectativa de êxito da parte é tão grande que o ordenamento jurídico prefere que os efeitos deletérios da demora na tramitação do processo não onerem o autor que, a toda evidência, irá se sagrar vencedor ao final, mas sim o réu, que ao que tudo indica é quem irá ser derrotado (BRASIL, 2015).

Seja qual for a modalidade da tutela provisória, como o próprio nome já sugere, certo é que a decisão que a concede é uma decisão provisória e que, portanto, pode ser revista no curso do processo.

Assim sendo, a decisão que concede uma tutela provisória não tem aptidão para formar coisa julgada material, haja vista que as características da coisa julgada, sobretudo a de revestir a decisão de imutabilidade e de indiscutibilidade, fazem com que ela apenas possa acobertar uma decisão definitiva, não uma efêmera.

Afasta-se, assim, o principal fundamento pelo qual se reconheceu alhures que a rejeição do pedido autoral importa em concessão de tutela jurisdicional em favor do réu.

De igual forma, não se pode também cogitar de formação de título executivo judicial, pois a decisão que concede a tutela provisória é efêmera e a certeza, ao lado da liquidez e da exigibilidade, são características indispensáveis (THEODORO JÚNIOR, 2017, p. 59) a um título executivo.

Com isso, observa-se que os dois fundamentos para se afirmar que a improcedência de pedido formulado em ação não ambivalente gera consequências favoráveis para o réu não se apresentam quando do mero indeferimento da tutela provisória.

E mesmo no contexto das ações dúplices o quadro não é diverso. 
Nas ações propriamente dúplices, ou seja, naquelas nas quais a ação é ambivalente por força da relação jurídica de direito material posta em juízo, o indeferimento de pedido de tutela provisória por si só não tem o condão de influir na situação jurídica que existia antes da propositura da ação, seja para modificá-la, seja para determinar sua manutenção.

Com efeito, em uma ação possessória na qual o juiz tenha indeferido o pedido de tutela provisória apresentado pelo autor não é essa decisão que legitima a permanência do réu no local.

Na mesma linha, no caso de uma ação declaratória de inexistência de débito com pedido de tutela provisória para sustar um protesto ou para obstar uma cobrança, não é a decisão denegatória que serve de amparo para a manutenção do protesto ou para o prosseguimento da cobrança, mas sim situação jurídica que já existia antes da propositura da ação declaratória, que com o indeferimento da medida pleiteada em nada se alterou.

Mesmo nas ações dúplices de controle abstrato de constitucionalidade a decisão denegatória de tutela provisória não produz ela própria qualquer efeito.

Com efeito, apenas a decisão que concede a medida cautelar em ADI ou de ADC é dotada de eficácia contra todos e apta a vincular os demais órgãos do Poder Judiciário.

A decisão que indefere medida cautelar em sede de controle abstrato de constitucionalidade em nada inova no cenário jurídico, não impedindo que qualquer dos órgãos do Poder Judiciário aprecie livremente a compatibilidade formal e material dos dispositivos impugnados com a Constituição Federal.

Tanto é assim que o Supremo Tribunal Federal tem entendimento pacífico ${ }^{3}$ no sentido de não caber reclamação contra decisão emanada de outros órgãos jurisdicionais que Ihe são subordinados que tenha declarado determinada norma inconstitucional quando a referida norma já havia sido anteriormente impugnada em ADI na qual o STF indeferiu pedido de medida cautelar e que ainda pende de julgamento definitivo.

\footnotetext{
${ }^{3}$ Por todos, Rcl 2585 MC, Rel. Min, Marco Aurélio (BRASIL, 2004), Rcl 3.458, Rel. Min. Cezar Peluso (BRASIL, 2007) e Rcl 3347 AgR, Rel. Min, Rosa Weber (BRASIL, 2016b).

Revista Auditorium, Rio de Janeiro, v. 25, n. 52, p. 107-125, jul./out. 2021
} 
Isso ocorre porque nesse caso não há desrespeito algum à autoridade da decisão do Supremo Tribunal Federal, que se limitou a não conceder uma tutela provisória.

Como se vê, em todos esses casos o panorama jurídico consolidado após o indeferimento da tutela provisória é o mesmo que já se apresentava antes da apresentação da petição inicial.

A decisão denegatória da tutela provisória não cria qualquer direito para quem quer que seja, razão pela qual não há como se afirmar que ela possa implicar concessão de tutela jurisdicional em benefício do réu.

\section{CONCLUSÃO}

No caso de indeferimento de tutela provisória não se apresenta qualquer dos fundamentos que embasam o reconhecimento de que a rejeição do pedido autoral em sentença definitiva importa em concessão de tutela jurisdicional para a parte adversa.

A rigor, em sentido contrário, a efêmera decisão denegatória de tutela provisória não tem aptidão para produzir efeitos que de qualquer forma influem na relação jurídica de direito material controvertida no processo.

Conclui-se, portanto, que a decisão que indefere tutela provisória requerida pelo autor não pode ser compreendida como uma expressão da tutela de direitos pela via jurisdicional em favor do réu. 


\section{REFERÊNCIAS}

ALVIM, Arruda. Manual de Direito Processual Civil. 19. ed. rev. atual. e ampl. São Paulo: Revista dos Tribunais, 2020.

BRASIL. [Constituição (1988)]. Constituição da República Federativa do Brasil de 1988. Brasília, DF: Presidência da República, [2020]. Disponível em: http://www.planalto.gov.br/ccivil_03/constituicao/constituicao.htm. Acesso em: 27 jul. 2021.

BRASIL. Decreto-Lei no 4.657, de 4 de setembro de 1942. Lei de Introdução às normas do Direito Brasileiro. Brasília, DF: Presidência da República, 4 set. 1942. Disponível em

http://www.planalto.gov.br/ccivil_03/decreto-lei/del4657compilado.htm. Acesso em: 25 ago. 2021.

BRASIL. Lei no 13.105, de 16 de março de 2015. Código de Processo Civil. Brasília, DF: Presidência da República, 16 mar. 2015. Disponível em http://www.planalto.gov.br/ccivil_03/_ato2015-2018/2015/lei/l13105.htm. Acesso em: 25 ago. 2021.

BRASIL. Superior Tribunal de Justiça. Corte Especial. Recurso Especial 1.324.152. Processo civil. Recurso especial representativo da controvérsia. Art.543-CDO CPC. Exequibilidade de sentenças não condenatórias. Artigo 475-N, I, do CPC. Relator: Min. Luis Felipe Salomão. Relator do acórdão: Min. Francisco Falcão, 4 de maio de 2016. Revista Eletrônica de Jurisprudência, Brasília, não paginado, 15 jun. 2016. Disponível em: https://stj.jusbrasil.com.br/jurisprudencia/349598325/recurso-especial-resp-1324152 -sp-2012-0099874-4. Acesso em: 28 out. 2021.

BRASIL. Supremo Tribunal Federal. Tribunal Pleno, Rcl 2585 MC, Rel. Min, Marco Aurélio, julgado em 23/09/2004.

BRASIL. Supremo Tribunal Federal. Tribunal Pleno, Rcl 3458 AgR, Rel. Min. Cezar Peluso, julgado em 29/10/2007.

BRASIL. Supremo Tribunal Federal. Primeira Turma. Rcl 3347 AgR, Rel. Min, Rosa Weber, julgado em 01/03/2016b.

BUENO, Cassio Scarpinella. Manual de Direito Processual Civil. 6. ed. São Paulo: Saraiva, 2020.

CÂMARA, Alexandre Freitas. O Novo Processo Civil Brasileiro. 3. ed. São Paulo: Atlas, 2017.

CINTRA, Antonio Carlos de Araújo; GRINOVER, Ada Pellegrini; DINAMARCO, Cândido Rangel. Teoria Geral do Processo. 29. ed. São Paulo: Malheiros, 2013. 
DONIZETTI, Elpídio. Curso de Direito Processual Civil Comentado. 23. ed. rev., atual. e ampl. São Paulo: Atlas, 2020.

DONIZETTI, Elpídio. Novo Código de Processo Civil Comentado. 2. ed. rev. atual. e ampl. São Paulo: Atlas, 2017.

GONÇALVES, Marcus Vinicius Rios. Curso de Direito Processual Civil. 17. ed. São Paulo: Saraiva, 2020. v. 1.

GUIMARÃES, Deocleciano Torrieri. Dicionário Jurídico. Atualizado por Ana Claudia Schwenck dos Santos. 23. ed. São Paulo: Rideel, 2019.

DIDIER JÚNIOR, Fredie. Curso de direito processual civil. 19. ed. rev., atual. e ampl. Salvador: JusPodivm, 2017. v. 1.

MARINONI, Luiz Guilherme; ARENHART, Sérgio Cruz; MITIDIERO, Daniel. Curso de Processo Civil. 3. ed. rev. atual. e ampl. São Paulo: Revista dos Tribunais, 2017a. v. 2.

MARINONI, Luiz Guilherme; ARENHART, Sérgio Cruz; MITIDIERO, Daniel. Novo Código de Processo Civil Comentado. 3. ed. rev. atual. e ampl. São Paulo: Revista dos Tribunais, 2017b.

MENDES, Gilmar Ferreira; COELHO, Inocêncio Mártires; BRANCO, Paulo Gustavo Gonet. Curso de Direito Constitucional. 5. ed. rev. e atual. São Paulo: Saraiva; Brasília: IDP, 2010.

MORAES, Alexandre de. Direito Constitucional. 20. ed., São Paulo: Atlas, 2006.

MEDINA, José Miguel Garcia. Curso de Direito Processual Civil Moderno. 3. ed. rev. ampl. atual., São Paulo: Revista dos Tribunais, 2017.

NEVES, Daniel Amorim Assumpção. Manual de Direito Processual Civil. Volume único. 6. ed. Salvador: Método, 2014.

THEODORO JÚNIOR, Humberto. Curso de Direito Processual Civil. 44. ed. rev. e atual. Rio de Janeiro: Forense, 2017. v. 1

atual. Rio de Janeiro: Forense, 2017. v. 3

Curso de Direito Processual Civil. 44. ed. rev. e 